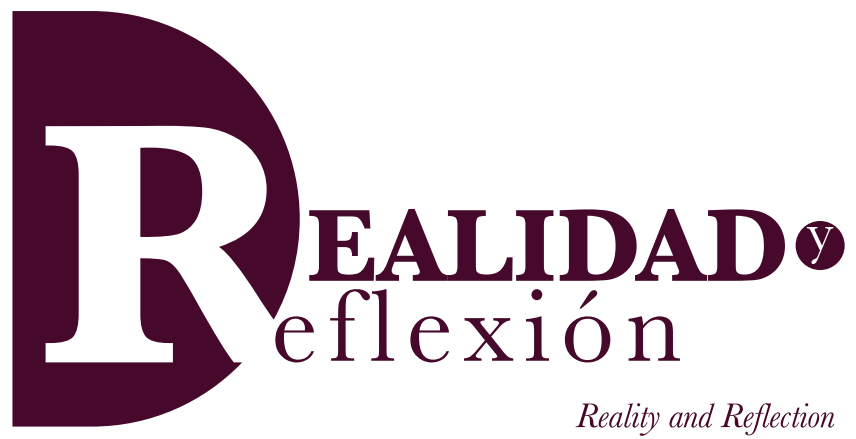

ISSN 1992-6510

Año 20, N 52, San Salvador, El Salvador, Centroamérica. Revista Semestral Julio-Diciembre 2020

YEAR 20, N 52, SAN SALVADOR, EL SALVADOR, CENTRAL AMERICA. SEMESTRAL JOURNAL JULY-DECEMBER 2020

\title{
Caravanas migrantes centroamericanas: ¿y dónde está el SICA?
}

¿Hasta qué punto el SICA ha intervenido con políticas migratorias y sociales para evitar las olas de migración de la región centroamericana hacia Norte América?

Central American Migrant Caravans: ¿ Where's the Central American Integration System?

$\dot{i}$ To what extent has the SICA intervened with migration and social policies to avoid the mass migration from Central to North America?

José Hernán Serpas Comas

Doctor en Derecho por la Universidad Autónoma de Barcelona Docente Tiempo Completo en la Universidad Francisco Gavidia Investigador Asociado al Observatorio de Políticas Públicas de la Universidad Francisco Gavidia jserpas@ufg.edu.sv 


\section{RESUMEN}

El objetivo del presente trabajo es analizar la falta de políticas migratorias y sociales del Sistema de Integración Centroamericano (SICA) con el fin de evitar las olas de migración denominadas Caravanas migrantes. Para lograr hacer un análisis jurídico, empírico y objetivo se hace, necesariamente, una definición de las caravanas migrantes y posteriormente, se analiza el cuerpo jurídico del que dispone el SICA para evitar dichos éxodos. Finalmente, se hace un análisis del reciente Pacto Mundial para la Migración Segura, Ordenada y Regular firmada por muchos países miembros de la ONU y como este puede crear un marco jurídico para que el Parlamento Centroamericano pueda crear leyes tanto para evitar la migración como para proteger a los que emigran.

Palabras clave: Caravanas migrantes, SICA, legislación migratoria, políticas migratorias, derechos humanos, derechos migratorios.

\section{ABSTRACT:}

The main objective of this paper is to analyze the lack of migration and social policies from the Central American Integration System (SICA) towards the eradication of the waves of migrants also known as 'Migrant caravans'. To achieve a juridical, empirical and objective analysis it is necessary to define the Migrant caravans to later analyze the legal tools that the CAIS has to avoid and eradicate such caravans. Finally, the new 'Global Compact for Safe, Orderly and Regular Migration' signed by many of the UN countries is put under the magnifying glass to determine how it can provide the SICA with the necessary legal framework to avoid irregular migration in masses and, in case of failing, how it can protect migrants in their journeys.

Key words: Migrant caravans, SICA, migration legislation, migration policies, human rights, migrating rights. 


\section{Introducción}

Aunque la migración centroamericana es un fenómeno social relativamente antiguo, las caravanas migrantes centroamericanas son algo completamente nuevo. Originándose en las redes sociales, las caravanas han tenido un auge tremendo con consecuencias políticas y jurídicas que han cambiado para siempre el panorama internacional.

Este texto trata, desde una perspectiva jurídica analítica, sobre el involucramiento del SICA y de los gobiernos locales en cuanto a la migración en masa se refiere. Así pues, se hace una reflexión sobre los motivos que causan el éxodo de personas.

Profundizando más, este artículo aborda sistemáticamente esta nueva tipología de migración, desde sus orígenes políticos y sociales, hasta sus repercusiones internacionales. Sobre todo, se analiza la postura (legislación y políticas) del Sistema de Integración Centroamericano (SICA) en la materia.

La crisis de la región centroamericana ha repercutido de forma directa en la población, en especial en aquella localizada en el Triángulo Norte. Esto marca una clara correlación entre la migración en masa y la zona geográfica más afectada por la falta de cohesión social, la falta de seguridad jurídica y personal, el poco desarrollo económico y un medioambiente pobre.

Se analizan entonces las problemáticas antes mencionadas y se desarrolla la correlación entre ellas y el nacimiento de las caravanas migrantes. Aunque plantear estas cuestiones es importante, resulta de mayor interés saber el involucramiento del SICA en la prevención de las problemáticas que llevan a los centroamericanos a migrar a Estados Unidos y Canadá.

En otras palabras: ¿qué hace el SICA para mejorar las condiciones del Triángulo Norte?

Con esta cuestión en mente, surge el objetivo principal: averiguar hasta qué punto se involucra la supranacional en la problemática de la migración centroamericana.

La hipótesis es que la legislación actual del SICA es amplia en algunos de los factores que generan estos éxodos, pero se prevé que la supranacional no cuenta con los mecanismos para hacerla valer. Es decir que el SICA cuenta con los instrumentos legales para evitar la migración en masa, pero estos no cuentan con el respaldo institucional real.

Luego de hacer el análisis correspondiente se recomienda que se generen espacios de cooperación e intercambio de buenas prácticas a nivel nacional y transnacional para hacer valer el instrumental jurídico y prevenir estos desplazamientos forzosos.

Es lógico deducir que la problemática no se resolverá a corto plazo y que, mientras se inicia la implementación de los mecanismos antes propuestos, la migración en masa seguirá sucediendo. Por ello, se propone al SICA que se legisle para que se respeten los derechos de las personas que deciden migrar.

Para lograr el respeto de los derechos de los migrantes, el SICA debe buscar alianzas internacionales, especialmente con los países de 
paso (Guatemala, México y en algunos casos, Estados Unidos) y los países destino (México, Estados Unidos y Canadá). En otras palabras, se debe proteger la migración, más no alentarla.

Además, se analiza el acuerdo global de la ONU titulado Pacto Mundial para la Migración Segura, Ordenada y Regular para saber hasta qué punto es funcional y su impacto verdadero en la realidad migratoria centroamericana. En ese sentido, se busca ver cómo el Pacto puede facilitar la migración y la movilidad ordenadas, seguras, regulares y responsables de las personas; incluso, mediante la aplicación de políticas migratorias planificadas y bien gestionadas.

El artículo concluye, entre otras cosas, que se tiene que utilizar el recurso de la cooperación internacional para mejorar las condiciones del Triángulo Norte centroamericano y evitar la fuga del capital humano al norte del continente. También que, desde la academia, como parte de la sociedad civil, debemos proponer acciones para prevenir la migración y en su defecto, apoyar a las personas que deciden migrar.Además, se propone la realización de un estudio sociohumanístico sobre el desenlace de sus travesías.

\section{Marco teórico}

En los últimos meses ha habido varias caravanas migrantes originarias de Centroamérica con destino a los Estados Unidos. Estos inmigrantes deciden huir de los problemas sociales que viven a diario y son impulsados por la esperanza de encontrar más y mejores oportunidades lejos de sus tierras. Ahora bien, los gobiernos y el SICA deben tener claro que la migración debe ser una opción más y no una salida forzada por las circunstancias de violencia, pobreza y falta de oportunidades.

Aunque existieron varias caravanas previas, la precursora directa de la nueva forma migratoria fue la denominada "Vía Crucis del Migrante", la cual fue una caravana que comenzó su recorrido en el estado de Chiapas, México, en donde más de mil quinientas personas buscaban atravesar México. A diferencia de las caravanas a las que me refiero en la presente investigación, no pretendía entrar a territorio estadounidense, sino más bien crear una consciencia de la travesía que millones de centroamericanos pasaban.

El Vía Crucis del Migrante causó una gran repercusión con su recorrido por México en 2018, pero hay que destacar que no fue la primera caravana de su tipo. Dichas movilizaciones se han realizado desde hace más de diez años, pero en esta ocasión "lograron una gran visibilidad debido, principalmente, al gran número de participantes y a la atención que recibió del presidente Donald Trump y de los medios de comunicación" (Martínez Hernández-Mejía, 2018)

Así el Vía Crucis del Migrante fue un detonante para el fenómeno social internacional de lo que hoy conocemos como Caravanas migrantes. Es aquí donde surge la pregunta: ¿Qué son las Caravanas Migrantes? la respuesta a esta cuestión es amplia, pues no son simplemente una movilización masiva de personas, sino que tienen una serie de rasgos y características que las identifican, entre las que destacan las siguientes:

- Son grupos grandes de personas que oscilan entre las 250 y las 2,000. 
- Se originan en el Triángulo Norte centroamericano.

- Los países de paso de las caravanas son los centroamericanos y México.

- El destino final de las caravanas es Estados Unidos y en su defecto, México.

- Tienen una amplia cobertura y repercusión mediática.

- El objetivo principal es la migración pero también la de incidir en la política y crear una concientización de derechos humanos.

Cabe destacar que las últimas dos características van ligadas la una de la otra. Esto se debe a que las caravanas han hecho utilización de las redes sociales (Facebook, Twitter, YouTube e Instagram) y otros medios de comunicación, para tener cobertura del éxodo. Hasta la fecha se han registrado, en los diferentes medios de comunicación, seis caravanas migrantes originarias del Triángulo Norte con destino a los Estados Unidos. Cada una de estas caravanas ha tenido buena organización y gran repercusión social.

La primera de las Caravanas migrantes se inició con una reunión el 12 de octubre en San Pedro Sula, Honduras, y partió de esa ciudad a la mañana siguiente. Fue una organización de "más de mil gentes, que se fue haciendo masiva en el trayecto. Además, se fue generalizando con la suma de otros migrantes de pueblos vecinos de El Salvador y Guatemala, incluso de otros continentes, regiones y los propios pueblos mexicanos del suroeste” (Lera Mejía, 2018).
La segunda caravana partió desde la ciudad de Esquipulas, en Guatemala, el 21 de octubre de 2018 y estaba compuesta por 1,000 personas, la mayoría, hondureños. Este segundo grupo de migrantes también tuvo una gran repercusión en los medios de comunicación por su intento fallido de cruzar la frontera entre Guatemala y México. ${ }^{1}$

La tercera caravana compuesta de más de 300 personas salió de San Salvador el 28 de octubre de 2018. Tres días más tarde salió la cuarta caravana, compuesta de dos grupos de más de 300 personas $^{2}$ cada uno, también de San Salvador. La última caravana de 2018 salió el 5 de noviembre de San Salvador y estaba formada por alrededor de 240 personas.

Pasaron las semanas y se pensaba que estos éxodos habían concluido, pero el 14 de enero de 2019 más de 500 hondureños partieron en caravana desde San Pedro Sula y en el camino se les unieron más de 1,500 personas, siendo así la sexta caravana migrante. Según datos de ACNUR, de las más de 16,000 personas desplazadas en las caravanas, el 49\% son hondureños; 38\%, salvadoreños y el resto son guatemaltecos y algunos de otros países de la región. Surge de esta manera una correlación obvia entre las Caravanas migrantes y el origen de las mismas: todas las caravanas han surgido de las tres ciudades más violentas de Centroamérica. Esta información se puede ver reflejada con la siguiente tabla:

\footnotetext{
1 El 28 de octubre de 2018 la segunda caravana de migrantes centroamericanos intentó cruzar la frontera entre Guatemala y México, pero, según reportes de diferentes medios de comunicación, la policía federal mexicana les retuvo con gas lacrimógeno y balas de goma. En ese incidente salieron lesionadas varias personas y murió un hondureño de 26 años de edad. (E1 Sol de México, 2018)

2 Algunas fuentes como Europa Press reportaron que fueron casi 2,000 personas las que salieron de San Salvador en diferentes grupos. (Europa Press, 2018)
} 


\begin{tabular}{c|c|c|c|c|c}
\hline Ciudad & Homicidios & Habitantes & Tasa & $\begin{array}{c}\text { Posición de } \\
\text { violencia a nivel } \\
\text { regional }\end{array}$ & $\begin{array}{c}\text { Posición de } \\
\text { violencia a nivel } \\
\text { mundial }\end{array}$ \\
\hline San Salvador & 1.057 & 1.789 .588 & 59.06 & 1 & 17 \\
\hline Guatemala & 1.705 & 3.187 .293 & 53.49 & 2 & 24 \\
\hline San Pedro Sula & 392 & 765.864 & 51.18 & 3 & 26 \\
\hline
\end{tabular}

Fuente: Elaboración propia con datos del Banco Interamericano de Desarrollo (Buvinic, Morrison, \& Shifter, 2018).

Ahora bien, las ciudades de San Salvador, San Pedro Sula y Guatemala no solo son de las más violentas, sino que también se le unen otros factores como la falta de cohesión social, el poco desarrollo económico, un medioambiente pobre, la falta de seguridad (jurídica y personal) y la no presencia de las diversas instituciones estatales. La mezcla de todos estos elementos son los que propician el clima adecuado para que las personas que habitan esa zona decidan migrar donde tengan mejores oportunidades de una vida digna.

Los Estados Unidos es el destino por excelencia de los centroamericanos en aras de encontrar las oportunidades del sueño americano. El problema suscita con el refuerzo de las fronteras por parte del presidente Donald Trump. Los mecanismos para evitar la entrada irregular al país norteamericano y los controles migratorios se han fortalecido por parte del gobierno norteamericano e incluso, el presidente declaró que "los militares los están esperando". ${ }^{3}$

Por esta situación la mayoría de personas que componen las caravanas deciden solicitar asilo en México. Según un reporte de ACNUR, "más

3 Declaraciones del Presidente Donald Trump recabadas en la BBC. (BBC News, 2018). de 3,300 personas de esos grupos organizados han solicitado el reconocimiento del estatus de refugiado" (UNHCR ACNUR, 2018).

Esta crisis migratoria en México ha hecho saltar las alarmas al nuevo gobierno de Andrés Manuel López Obrador quien fue forzado, por el Gobierno de Estados Unidos y por la afluencia de migrantes, a cerrar la frontera con Guatemala. En ese puente fronterizo "miles de personas permanecieron hacinadas durante días (...) generando un caos en la frontera y llevando a muchos a optar por cruzar a nado. Aunque algunos regresaron, la mayoría de migrantes siguieron la peregrinación hacia el norte. Miles continúan aguardando en los pasos de Mexicali y Tijuana para solicitar asilo en EE. UU., una espera que podría llevar meses y posiblemente será infructuosa" (Martínez \& Briscoe, 2019).

La renuncia de los Estados Unidos a dejar entrar a los migrantes y su interés en que se mantengan en México para procesar sus solicitudes de asilo es una ficha clave de negociación entre los gobiernos norteamericanos. Por ello este problema debe ser atendido de forma comprensiva por medio de un plan que incluya a Estados Unidos, México y los países centroamericanos. Estos últimos deberían hacerlo por medio del SICA para tener mayor presencia internacional. Es más fácil y factible 
negociar como bloque que hacerlo de manera dispar e individual.

Según el artículo 2 del Protocolo de Tegucigalpa, "El Sistema de la Integración Centroamericana es el marco institucional de la Integración Regional de Centroamérica" (PROTOCOLO DE TEGUCIGALPA, 1991). Es decir, que es un grupo de instituciones que tienen varios objetivos, entre los que destacan: consolidar las democracias de la región centroamericana respetando derechos humanos; concretar nuevos modelos de seguridad regional; impulsar un régimen amplio de libertad; y lograr un sistema regional de bienestar y justicia económica.

De esta forma, el SICA se consolida como un instrumento de mucho valor para el desarrollo de la región centroamericana, el problema suscita en que no sabemos aprovechar sus instituciones y marco legal a su máximo potencial. Esto se hace evidente en la falta de intervención del organismo supranacional en el caso de la migración centroamericana. Sus políticas sociales para el desarrollo de regiones más pobres en el triángulo norte de Centroamérica son pocas, y su intervención en los procesos de firma de tratados para mejorar las condiciones de vida de los migrantes con terceros países es mínima.

\section{Causales de migración en masa y las herramientas del SICA para evitarla}

Existen diversas leyes y políticas públicas a disposición del SICA y los gobiernos Estatales de cada uno de los países del triángulo norte centroamericano para evitar la migración en masa.
Habría que hacer un análisis de los problemas que generan la migración para saber cuáles son las herramientas a utilizar en cada caso.

Como se dijo en el marco teórico, son:

- La falta de cohesión social.

- La falta de seguridad jurídica y personal.

- El poco desarrollo económico.

- Un medioambiente pobre.

\section{La cohesión social}

La cohesión social la define el Banco Interamericano de Desarrollo como: "la suma del conjunto de externalidades positivas que genera el capital social, más la suma de factores que fomentan el equilibrio en la distribución de oportunidades entre los individuos" (Banco Interamericano de Desarrollo, 2006). Por su parte, la Comisión Económica para América Latina (CEPAL) agrega unos elementos a esta definición y dice que la cohesión social es "la dialéctica entre mecanismos instituidos de inclusión y exclusión sociales y las respuestas, percepciones y disposiciones de la ciudadanía frente al modo en que estos operan" (CEPAL, 2007).

El caso de Centroamérica, específicamente el Triángulo Norte, no hay suficiente capital social y no existe una suma de factores que equilibren las oportunidades que tienen los individuos. Los mecanismos que las instituciones, estatales y regionales no aportan sistemas de inclusión social y además las respuestas de la ciudadanía son mínimas o no existentes. El autor Carlos Sojo califica esta situación en Centroamérica como: "nuestra excluyente cohesión social" (Sojo, 2007). 
Esta falta de cohesión social es uno de los principales problemas que Centroamérica tiene para con su población ya que da pie a la migración en general y, además, actualmente es un catalizador para la migración en masa. Para mejorar esta situación, y tener una base social y jurídica homogénea en todos los países de la región, se crearon los Objetivos de las Bases para una Política Social Centroamericana, y son:

1. Promover en forma armónica y equilibrada el desarrollo sostenible de la región basado en la superación de la pobreza, la participación activa de la sociedad civil organizada y la ciudadanía en general, así como la conservación del medioambiente y el uso racional de los recursos naturales.

2. Propiciar las oportunidades para alcanzar el desarrollo de la población centroamericana de manera integral y sostenible en un marco de equidad, corresponsabilidad y autogestión a través del fomento de la solidaridad en las sociedades, y entre las sociedades, así como de la cooperación entre personas, familias, comunidades y pueblos de la región.

3. Crear un marco de convivencia social que asegure el pleno respeto de las garantías individuales y sociales, eliminando todas las prácticas de discriminación legal o, de hecho. (SISCA, 2009)

Ahora bien, la estrategia histórica del SICA para mejorar la cohesión social siempre fue la cooperación internacional, siendo los principales cooperadores Taiwán, la Agencia Española de Cooperación Internacional (AECID), el BID y el Banco Mundial, y funcionaba en paralelo a la Agenda Estratégica Social. Dicha Agenda giraba en torno a tres ejes: "1. Fortalecimiento de la institucionalidad social de Centroamérica; 2.Provisión efectiva de servicios sociales básicos y 3. Bienestar social y desarrollo humano".

Una de las cosas que se ha mantenido de esta agenda es la ejecución del fondo estructural de cohesión social, la cual se hace de la siguiente manera: (Ver Tabla 1).

El sistema había venido presentando serias fallas en su implementación y se hace evidente a la hora de comparar los resultados de medición cronológica de los indicadores primarios de cohesión social establecidos por la CEPAL y son:

- Tasa de renta baja después de las transferencias (umbral fijado en el $60 \%$ de la renta mediana).

- Tasa de renta baja después de la recepción de transferencias, valores ilustrativos.

- Distribución de la renta (quintil 5/quintil 1).

- Persistencia de renta baja.

- Brecha de la renta baja mediana.

- Cohesión regional (dispersión de las tasas regionales de empleo).

- Tasa de desempleo de larga duración.

- Número de personas que viven en hogares en los que no trabaja ninguno de sus miembros.

- Número de personas que abandonan prematuramente la enseñanza y no siguen ningún tipo de educación o formación. 


\section{Tabla 1}

Ejecución del fondo estructural de cohesión social

La ejecución del fondo se destina a proyectos individuales o de país para los cuales podrán recibirse fondos reembolsables.
Asimismo, se considera financiar los estudios de prefactibilidad, factibilidad y diseño final de proyectos, inversiones fijas
de capital para obras de infraestructura, adquisición de bienes y servicios para la ejecución y operación de los proyectos,
proporcionando capital para la operación de los primeros años de funcionamiento de los proyectos.

Los recursos del Fondo se destinarán a programas en las siguientes áreas: seguridad alimentaria y nutricional, vivienda social y la afectada por contingencias, salud básica, atención a grupos vulnerables (niñez, adultos mayores, poblaciones indígenas), empleo digno, agua y saneamiento, fondos de garantía y avales (para micro y pequeña empresa y vivienda social), crédito para la micro, pequeña y mediana empresa, educación y cultura y atención a desastres naturales.

Los proyectos para su elegibilidad deben de cumplir con los criterios de pertinencia regional, inclusión en la función de los gabinetes sociales, coherencia y sostenibilidad. Asimismo, los ejecutores deben ser instancias con experiencia comprobada en la implementación de proyectos de desarrollo social, como: Órganos e instituciones del SICA, instituciones públicas nacionales, organizaciones de desarrollo como cooperativas, federaciones, fundaciones, asociaciones de desarrollo, que cuenten con el aval del gobierno o gobiernos del país o países en los cuales se desarrollará el proyecto

El aporte mínimo por proyecto será de US \$1 millón. La contrapartida será definida con el aportante y podría ser en especie. El Banco Centroamericano de Integración Económica (BCIE), dará apoyo técnico e institucional a los gobiernos y a la SISCA, para la implementación de la Agenda Estratégica Social del SICA y su estrategia de captación de recursos.

Fuente: Consejo de la Integración Social Centroamericana/Secretaría de la Integración Social Centroamericana. (CIS/SICA, 2009).

- Estudiantes de 15 años con bajo rendimiento en las pruebas de lectura.

- Esperanza de vida al nacer.

- Brecha de empleo de los inmigrantes (CEPAL, 2007).

Ante lo anterior se puede asegurar que los Estados de la región centroamericana se comprometen internacionalmente a mejorar sus condiciones de cohesión social "pero todavía disponen de capacidades limitadas para honrar plenamente sus propios compromisos e influir apropiadamente las prácticas de la sociedad" (Sojo, 2007).

En respuesta a la falta de resultados de la Agenda Estratégica Social y con el fin de que la región implemente más y mejores políticas públicas de cohesión social, el SICA puso en marcha, en junio de 2018, la Agenda Regional Intersectorial sobre Protección Social e Inclusión Productiva con Equidad (ARIPSIP). Esta Agenda es un instrumento estratégico que tiene por objetivo el desarrollar "estrategias intersectoriales que fortalezcan las capacidades de los países del SICA para incrementar la protección social e inclusión productiva de las presentes y futuras generaciones" (Técnico Intersectorial-Sica, 2018).

Se espera que esta nueva agenda dé resultados por medio de trabajos intersectoriales en cuatro líneas estratégicas:

1. El acceso universal y la cobertura universal, equitativa y articulada a los esquemas de protección social y servicios.

2. Capacidad productiva para la generación de empleo docente, emprendimiento $y$ empleabilidad, con enfoque sostenible. 
3. Territorios urbanos y rurales con dinámicas más productivas, inclusivas, resilientes y equitativas.

4. Gestión integral de la migración, bajo un enfoque de derechos y una óptica sistémica.

Para apreciar los detalles de la articulación de acciones en cada una de las líneas estratégicas consultar: Agenda Intersectorial Sobre Protección Social e Inclusión Productiva con Equidad (ARIPSIP) 2018-2030. ${ }^{4}$

Un factor muy positivo de La ARIPSIP es que se ha visto muy influenciada por la Agenda $2030^{5}$ que suscribieron varios países del mundo en 2016. Sus cuatro líneas estratégicas intentan estrechar brechas sociales y desarrollar las sociedades, siempre con un factor de sostenibilidad.

Por otro lado, los problemas que tendrá que afrontar el SICA con la implementación del ARIPSIP son los mismos que hace más de dos décadas, solo que en dimensiones diferentes y en un contexto globalizado: que los ricos no construyan una Centroamérica transnacionalizada y autoencerrada y; que los pobres no tengan que huir de ella.

\section{(in) Seguridad}

El problema de la inseguridad en Centroamérica, sobretodo en el Triángulo Norte, no es algo

\footnotetext{
4 https://www.sisca.int/centro-de-documentacion/marcoestrategico/1025-agenda-regional-intersectorial-sobre-proteccionsocial-e-inclusion-productiva-con-equidad-aripsip-2018-2030-1/file
}

5 La agenda 2030 para el desarrollo sostenible es "una hoja de ruta hacia un nuevo paradigma de desarrollo en el que las personas, el planeta, la prosperidad, la paz y las alianzas toman un rol central." (CEPAL, 2016) Esta Agenda incluye 17 Objetivos de Desarrollo Sostenible (ODS) y aunque no son jurídicamente obligatorios se prevé que los países los adopten como propios y establezcan marcos nacionales y/o regionales para su cumplimiento. nuevo, sino más bien un fenómeno viejo. " $\mathrm{La}$ violencia no es un concepto estático de único significado, por el contrario, es multifacético, porque se da en dimensiones micro o macro y es latente en campos de la economía, la política, la ideología, la cultura, la familia, en las instituciones, especialmente en las guerras, en la cuales se ha legitimado su uso a partir de diferentes fines, especialmente cuando los grupos humanos se ven obligados a competir por recursos en función de supervivencia o su seguridad" (Jiménez, 2012).

Según la oficina de Derechos Humanos del Arzobispado de Guatemala, la violencia en Centroamérica es causada por cinco factores: 1. Políticos: por la disminución del Estado, corrupción e ineficiencia; 2. Factores internacionales: transnacionalización del crimen y política para su combate; 3. Factores sociodemográficos: desigualdad, pobreza y problemas asociados; 4. Factores históricos: conflicto armado interno, estructuras e impunidad; y 5. Factores ideológicos: ideología individualista y consumista.

Según algunos autores como Guerrero y García (2012), "la situación actual de Centroamérica, específicamente en el Triángulo Norte, evidencia no solo la presencia de una violencia directa visible y que responde a actos de violencia específicos, sino a la violencia estructural en la que están los fundamentos del sistema y que se centra en el conjunto de estructuras que no permiten la satisfacción de las necesidades, llegando así a la negación de derechos”.

Existen varias formas para cuantificar la inseguridad que afecta gravemente la región 
centroamericana como cantidad de delitos de extorsión, secuestros, abusos (físicos, psicológicos y sexuales), o violaciones; pero la tasa de homicidios es la unidad de medición que nos pinta un panorama más amplio. La región es considerada de las más peligrosas en el mundo ${ }^{6}$ por su alto índice de homicidios y se puede apreciar en el siguiente gráfico: centroamericano podemos concluir que este es un factor decisivo a la hora de formar caravanas migrantes.

Para los problemas de la inseguridad en algunas zonas de Centroamérica se ha creado, entre otras leyes, la Estrategia de Seguridad Centroamericana, conocida como ESCA por sus

\section{Gráfico 1}

Homicidios por cada 100,000 habitantes en los países del Triángulo Norte centroamericano en 2014, 2016 y 2018

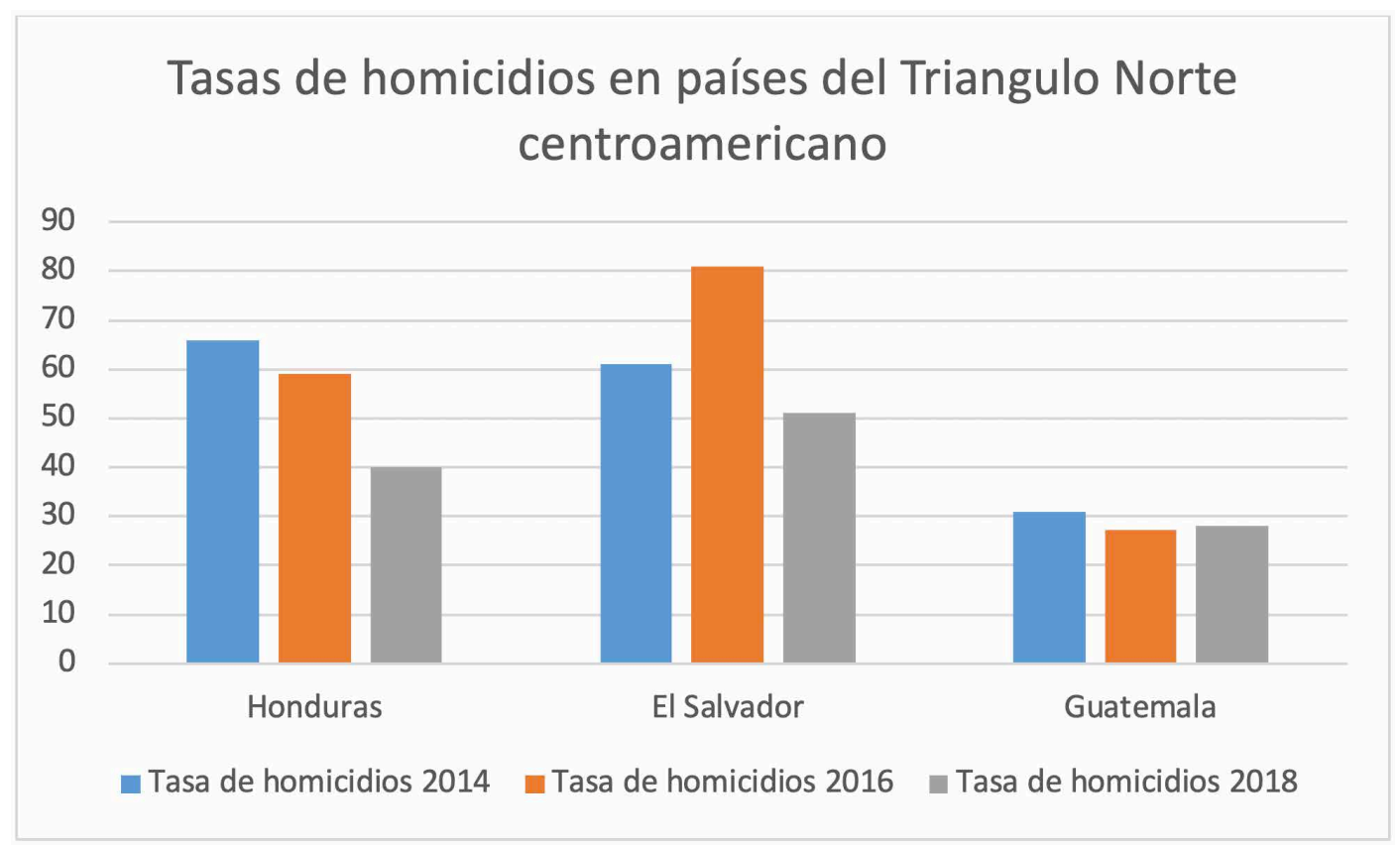

Fuente: Elaboración propia con datos del (Equipo Regional de Monitoreo y Análisis de Derechos Humanos en Centroamérica, 2019)

Teniendo esta estadística a la vista, es notable la correlación entre la violencia y la emigración, en su mayoría indocumentada. Es más, viendo los niveles de violencia en el Triángulo Norte siglas. El objetivo principal del proyecto ESCA es "propiciar el rol e incrementar la capacidad de los gobiernos locales en la formulación y ejecución de políticas y planes integrales de prevención social de la violencia en zonas transfronterizas" (AECID, 2018).

6 Excluyendo zonas de conflicto bélico. 
El ESCA tiene cuatro componentes:

1. El combate al delito: se concibe como un componente vital dentro del ESCA y pretende que los países centroamericanos realicen esfuerzos en conjunto para "la prevención, la represión, el control y sanción de todas las actividades ejecutadas por el crimen organizado y la delincuencia" (SICA, 2014).Los sistemas de información, el análisis estratégico e intercambio de inteligencia criminal son las herramientas principales que el ESCA proporciona a los Estados miembros para la consecución del objetivo principal. En el documento se identifican diez ámbitos especiales de atención para el combate al delito y son ${ }^{7}$ :

i. Delincuencia organizada.

ii. Combate al narcotráfico.

iii. Deportados con antecedentes penales o exconvictos.

iv. Pandillas.

v. Homicidio.

vi. Combate al tráfico ilícito de armas.

vii. Terrorismo.

viii. Corrupción.

ix. Otros temas policiales.

x. Aspectos legales.

2. La prevención de la violencia: Este componente fue elaborado para desarrollar el cuarto objetivo específico de la ESCA que dice: "Desarrollar políticas, programas, estrategias y acciones que permitan la prevención en los siguientes temas: violencia

7 Para mayor información sobre el componente del combate al delito se recomienda consultar la siguiente página web: https://www.sica. int/consulta/documento.aspx?idn=84016\&idm $=1$ \&IdEnt=1065 juvenil, violencia armada, violencia de género, tráfico ilícito y trata de personas, prevención desde lo local y los efectos de los desastres naturales en especial los provocados por el cambio climático".

3. La rehabilitación, reinserción y seguridad penitenciaria.

4. E1 fortalecimiento institucional.

Lo positivo del ESCA es que ha dado pie a la creación de las Estrategias Nacionales de Prevención a la Violencia. Estas son legislaciones nacionales de los países de la región centroamericana que logran establecer una visión regional. Además, hasta la finalización del primer periodo de vigencia del ESCA (2014) se habían realizado 22 proyectos con éxito.

Al contrario, la Estrategia de Seguridad Centroamericana fue aprobada en 2006 y no ha tenido mayores variantes. Es necesario hacer una revisión completa de la Estrategia y buscar nuevos aliados en la lucha contra la violencia.

\section{El desarrollo económico}

El factor de desarrollo económico es quizás del que existe más información cuantificable pues se trabaja con indicadores numéricos. Casi nada de la información existente en esta materia es cualitativa y por ende es más fácil de recabar y al no ser tan subjetivo se simplifica su análisis. Ante esta afluencia de información y para mostrar una imagen global de la situación económica en el Triángulo Norte centroamericano y como esta influye en la migración en masa, se tratarán únicamente dos temas: el primero, el 
Producto Interno Bruto de la zona y el segundo, la preocupante dependencia de las remesas familiares en la región.

El PIB es una unidad de medición que sirve para encontrar "el valor monetario de los bienes y servicios finales -es decir, los que adquiere el consumidor final- producidos por un país en un periodo de tiempo determinado (por ejemplo, un trimestre o un año), y cuenta todo el producto generado dentro de las fronteras" (Callen, 2008).

Para el presente artículo se toman como muestra los PIB de los países del Triángulo Norte centroamericano: El Salvador, Honduras y Guatemala. Además, se incluye en la muestra el PIB de Costa Rica. La justificación del muestreo realizado es que los países del Triángulo Norte son los que están bajo análisis al ser los países de origen de la migración en masa, mientras que Costa Rica sirve como una variable de control a la muestra del Triángulo Norte centroamericano, ya que aunque es parte de la misma región, no tiene indicios de migración en masa. En otras palabras, con el análisis del PIB se pondrá en evidencia cómo el lento crecimiento económico tiene una incidencia directa en la migración en masa.

En el siguiente gráfico (Ilustración 1) podemos apreciar el crecimiento lento del PIB en el triángulo norte centroamericano.

Se observa que el país que más crecimiento ha tenido en el Triángulo Norte centroamericano es Honduras, pero es también el país con el

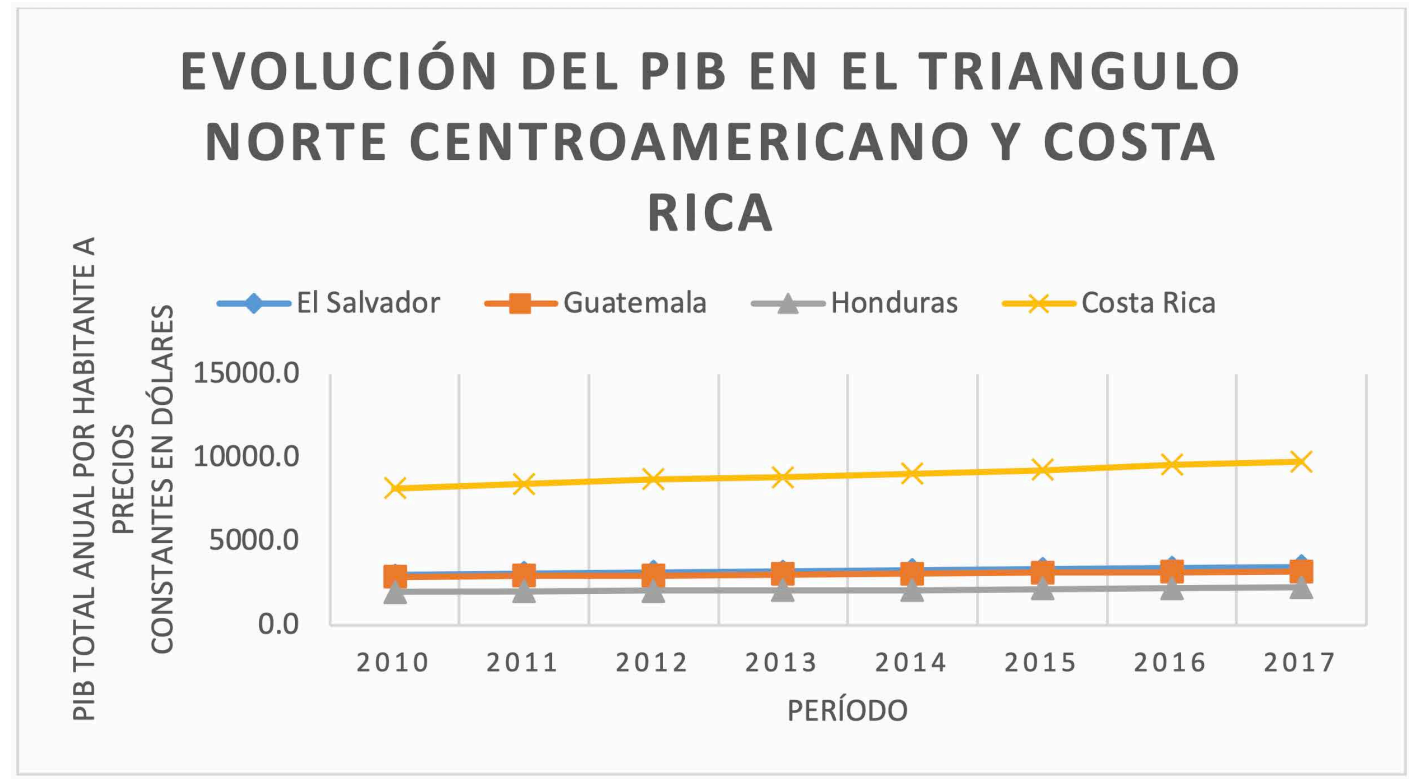

Ilustración 1. Evolución del Producto Interno Bruto en el Triángulo Norte Centroamericano y Costa Rica. Fuente: Elaboración propia con datos de CEPAL (CEPAL, 2019). 
PIB más bajo de la región. El mejor desempeño económico lo ha presentado Guatemala, aunque es difícil de apreciar en el gráfico, es el país que mejor desempeño tuvo en diferentes periodos, especialmente en 2015 y 2016. Aunque estos países han tenido mejoras en su PIB no se asemejan en nada a Costa Rica, es obvio que este último ha crecido de forma constante y se desprende por completo de los números del Triángulo Norte. Con la información antes expuesta se puede deducir que existe una correlación directa entre la situación de desarrollo económico y el flujo migratorio. Costa Rica tiene mayor crecimiento económico y producción de bienes y servicios; además, presenta una tasa de migración muy inferior. Lo opuesto ocurre en el Triángulo Norte, hay menos crecimiento económico y poca generación de productos y servicios, mientras que tienen un flujo emigrante muy alto.
Ahora bien, gran parte del crecimiento del PIB de los países del Triángulo Norte se debe al incremento en las remesas que reciben. Se estima que "las remesas representan más del 10\% del PIB de estos países” (Abuelafia, 2018). Es obvio que mientras más migración hay, crecen las remesas y los receptores de las remesas llegan a ser no productivos al depender de las mismas. Es en este punto donde radica la importancia de analizar el fenómeno del crecimiento de las remesas en paralelo a las olas de migración.

Las remesas son "recursos monetarios que los emigrantes obtienen trabajando en el extranjero y luego envían a su país natal" (Meyers, 2000). El siguiente gráfico muestra los datos de las remesas recibidas en los países del triángulo norte centroamericano y Costa Rica para mantener la muestra de los indicadores del PIB.

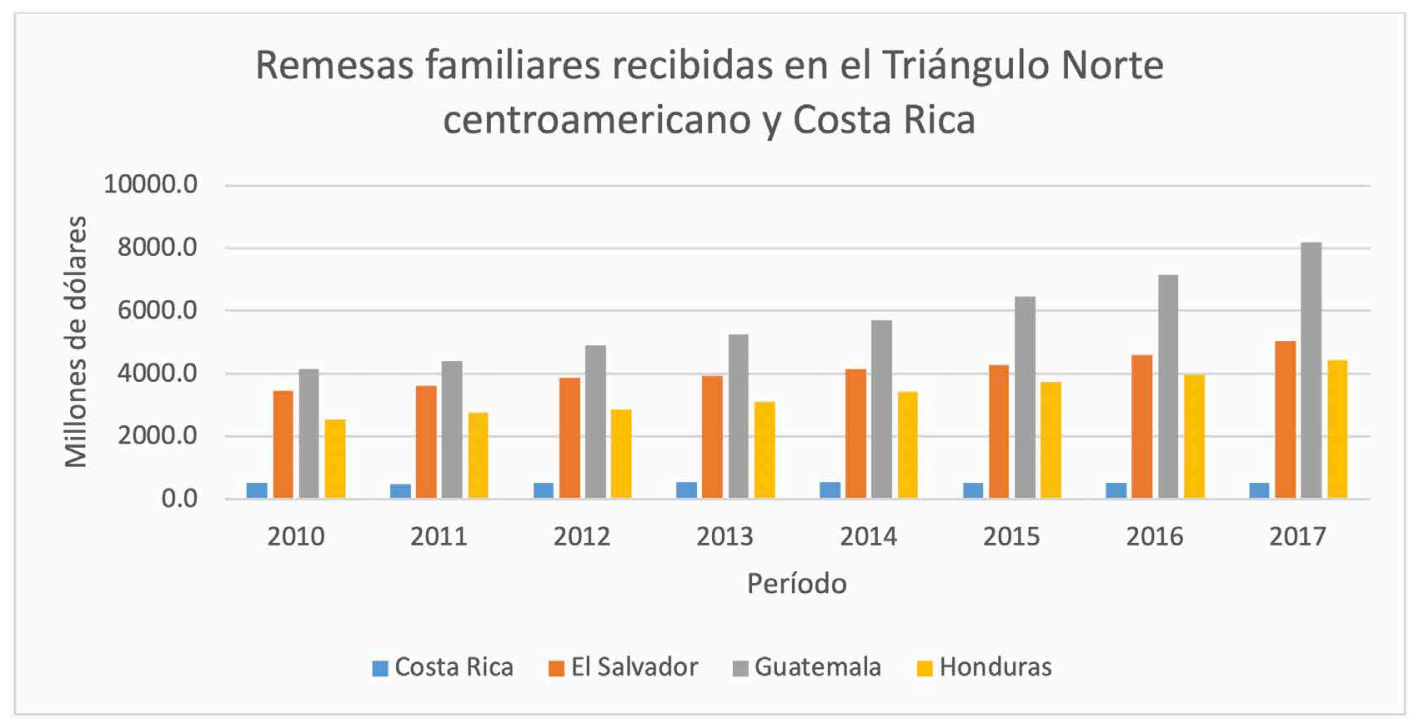

Ilustración 2. Gráfico de remesas familiares recibidas en el Triángulo Norte Centroamericano y Costa rica. Fuente: Elaboración propia con datos de SECMCA: Secretaría Ejecutiva del Consejo Monetario Centroamericano - Base de datos SIMAFIR - http://www.secmca.org/simafir.html 
La información recabada muestra un claro crecimiento de la recepción de remesas familiares en todos los países que componen la muestra. Lo que salta a la vista es que existe una diferencia abismal entre Costa Rica y el resto de países debido, entre otros factores, a que hay menos emigración de ese país y que su economía no depende de las remesas. Otra observación del gráfico es que Guatemala es el país que más depende de las remesas familiares y que más crecimiento ha tenido.

Lo positivo de las remesas para los países receptores es que aumenta significativamente el PIB y además proporcionan, según autores como De la Garza, Cortina y Ochoa (2005) una "fuente de financiamiento estable para microempresas". También ayudan a reducir los niveles de pobreza y elevan el poder adquisitivo de las personas con menos recursos.

Hay que destacar que, aunque las remesas ayudan a las personas receptoras a tener una afluencia económica y ayudan a satisfacer necesidades básicas de la población, "no son suficientes para elevar el ingreso de la población por encima de los niveles de pobreza"(Cortina et al., 2005).

Ante estas situaciones, el SICA tiene un órgano especializado en materia económica para velar por el desarrollo de la región y se denomina Secretaría de Integración Económica Centroamericana. Este órgano "vela por la correcta aplicación del Protocolo al Tratado General de Integración Económica Centroamericana (Protocolo de Guatemala) y demás instrumentos jurídicos de la integración económica regional, así como por la ejecución de las decisiones de los órganos del Subsistema Económico" (SIECA, 2019).
La migración en masa que tiene como causal el bajo desarrollo económico se puede disminuir con el fortalecimiento de políticas públicas regionales y locales ya existentes y la creación de nuevas en áreas de necesidad. Deben profundizar la integración económica y fortalecer las cadenas regionales de valor.

Algunos de los proyectos del SIECA que están en ejecución, para ayudar al crecimiento económico, actualmente son:

- Proyecto Regional de Apoyo a la Integración Económica Centroamericana y a la implementación del Acuerdo de Asociación (PRAIAA) - UE.

- Proyecto Fortaleciendo la Política Comercial Centroamericana - UE.

- Programa de Apoyo al acceso de la MIPYME al Mercado Regional.

- Integración Regional Centroamericana.

- Impulso a la innovación, vinculación con redes empresariales a nivel mundial y el emprendimiento de la región Centroamericana (ADESEP).

Con estos y otros proyectos no enumerados en ejecución, la SIECA pretende ayudar al fortalecimiento de las economías del Triángulo Norte centroamericano, impulsar sus economías y evitar que sean tan dependientes de las remesas familiares.

Dicho lo anterior se hace la recomendación que la SIECA debe tener en cuenta que las remesas son 
esenciales para satisfacer las necesidades básicas de las familias receptoras, pero deben juzgarse como una ayuda extra y no reemplazan la necesidad de políticas regionales para reducir la pobreza. Además, las remesas no deben considerarse como reemplazo de líneas de microcrédito para ayudar a las microempresas, sino que se deben reforzar las instituciones bancarias y financieras para capitalizar proyectos de inversión.

\section{Medioambiente}

Centroamérica es una región con una gran biodiversidad según datos recolectados contiene "el 8\% de la biodiversidad biológica mundial distribuida en 206 ecosistemas, 33 ecorregiones y 20 zonas de vida. Posee alrededor del 12\% de las costas de Latinoamérica y el Caribe, incluyendo 567,000 ha de manglares, 1,600 km de arrecifes coralinos" (CCAD, 2008).

Ahora bien, la gestión de esta biodiversidad se ve afectada por la forma en la que se ha dividido la tierra dentro de la sociedad, la densidad de la población, la desigualdad, la migración interna y externa y la pobreza. Otro factor que ha afectado el medioambiente es la mala práctica de producción agrícola e industrial. naturales y contaminación (atmosférica, hídrica, del suelo, del subsuelo, visual, lumínica y acústica, entre otros) y a su vez, crean una degradación del medioambiente en la región.

Agregado a esta degradación del medioambiente está el problema de las últimas sequias en el Triángulo Norte. Dicho problema se ha agravado en los últimos años, y con la constante presencia del fenómeno El Niño, que se le denomina "el corredor seco centroamericano" (CSC). Este corredor abarca desde el sur de México, Guatemala, El Salvador, Nicaragua, Honduras y el norte de Costa Rica; y afecta, según datos del $\mathrm{SICA}^{8}$, a más de 2.2 millones de personas.

Es de esta forma que el cambio climático se ha consolidado como una de las principales causas de la emigración de la región centroamericana en los últimos años, y es en definitiva un factor contribuyente a la formación de las caravanas migrantes. Incluso en 2015 el Programa Mundial de Alimentos (PMA), la Organización Internacional para las Migraciones (OIM) y London School of Economics realizaron un estudio donde se encontró una relación causal entre el cambio climático y la migración centroamericana.
Prácticas

productivas

(agrícolas e industriales)
Sobreexplotación

de recursos

naturales y

contaminación
Degradación

ambiental
El diagrama de flujo anterior demuestra gráficamente que las prácticas productivas generan una sobreexplotación de recursos
8 Datos consultados de la página web del programa de sistemas de información para la resiliencia en seguridad alimentaria y nutricional de la región del SICA, última consulta realizada el 02 de mayo de 2019: http://www.sica.int/consulta/noticia. aspx?idn=117798\&idm=1\&ident $=1461$ 
La Comisión Centroamericana de Ambiente y Desarrollo (CCAD) "fue constituida con la misión de desarrollar un régimen regional de cooperación e integración ambiental que contribuya a mejorar la calidad de vida de las poblaciones de sus Estados Miembros. $\mathrm{Su}$ accionar ha respondido a los Planes Ambientales de la Región Centroamericana" (CCAD, 2013).

El SICA, por su parte, ha hecho diversos esfuerzos históricos para disminuir el cambio climático, mejorar el CSC y reducir los efectos del fenómeno El Niño. Desde su creación, el SICA, ha creado diversas políticas públicas regionales y tratados internacionales para la protección y cuidado del medioambiente. El primer instrumento de este tipo fue el Plan Ambiental de la Región Centroamericana (PARCA), este primer intento de crear legislación ambiental, como veremos, tuvo poco impacto. Lo bueno del PARCA es que sentó las bases para futuros instrumentos homónimos, pero cada vez más profundos y permitían un mayor rango de actuación a las autoridades competentes en la materia.

Al expirar la tercera edición del PARCA "los presidentes de los Estados miembros decidieron apoyar una nueva herramienta, la cual es llamada Estrategia Regional Ambiental Marco" (Bonilla Silva, 2017). Este documento está vigente hasta 2020 e incluye seis temáticas primarias para generar iniciativas y acciones para promover la integración ambiental en la región de forma sostenible.

La Estrategia Regional Ambiental Marco tiene unas líneas de acción general y son:
- Cambio climático y sus gestiones de riesgo.

- La protección de los bosques.

- Mares.

- Biodiversidad.

- Recursos hídricos.

Además, para el correcto cumplimiento de las líneas de acción se agregan líneas de fomento al comercio y ambiente a través de la ecoeficiencia y fomento de uso de energías limpias. Agregado a esto, se incluyen "ejes transversales como los mecanismos financieros, lo que permiten que sean sustentables y con impactos positivos para el cuidado del medio ambiente en Centroamérica y el Caribe" (Bonilla Silva, 2017).

Existe también un instrumento para tratar de contrarrestar los efectos negativos del CSC y ayudar a las familias afectadas por el fenómeno y se denomina "Marco Estratégico Regional para la Gestión de Riesgos Climáticos en el Sector Agrícola del Corredor Seco Centroamericano". Este Marco Estratégico actúa a nivel Estatal y Regional y crea una gestión de riesgos climáticos y provee de procesos de adaptación de la agricultura ante el cambio climático.

Además de la creación de instrumentos y políticas públicas, se realizan esfuerzos por parte de los gobiernos Estatales con ayuda del Consejo Agropecuario Centroamericano (CAC), la ya mencionada CCAD y el Centro de Coordinación para la Prevención de Desastres Naturales en América Central (CEPREDENAC) entre otras organizaciones, para disminuir los problemas medioambientales.

Como nota final se debe destacar que, ante un problema tan grave como es el cambio 
climático y el deterioro del medioambiente, cualquier esfuerzo es poco. Incluso contando con financiamiento de Estados Unidos, de la Unión Europea y de China, Centroamérica no ha podido disminuir el impacto de la sobreexplotación y la contaminación. La única recomendación que se puede hacer en este punto tan delicado es que el SICA debe hacer todo lo posible por ceñirse a la Agenda 2030 y continuar con la línea de actuación que tiene a la fecha.

\section{¿Y si deciden migrar?: Herramientas del SICA para ayudar a los migrantes en su travesía}

Se ha venido hablando sobre cómo el SICA debe evitar la migración irregular en masa, pero se debe tener en cuenta también lo que el organismo internacional puede hacer a favor de las personas que se deciden finalmente a migrar, sobre todo en cuanto de derechos humanos se refiere. Se debe aclarar, necesariamente, que a lo largo de este capítulo se hablará de 'migración' en el sentido amplio de la palabra, es decir que incluye tanto a la migración regular (documentada) como la migración irregular (no documentada).

\section{Marco jurídico y herramientas del SICA para proteger a los migrantes}

La migración centroamericana, en especial hacia Estados Unidos y Europa, aumentó significativamente en los años 80 y 90 debido a los conflictos bélicos que la región estaba sufriendo. Las personas decidían migrar en busca de estabilidad social y en busca de nuevos horizontes económicos.

En medio de este clima de inestabilidad y migración es que se crea, en 1990, la
Comisión Centroamericana de Directores de Migración (OCAM) y es así que la ayuda a los centroamericanos que deciden migrar, intra o extra regionalmente, se ve institucionalizada.

Este organismo se constituye, según el artículo tercero de su Reglamento Interno, por "un Directorio integrado por los Director(a)s de Migración de los países de Centroamérica en calidad de Representantes Titulares" (OCAM, 2000). Sus funciones principales giran en torno a 3 temas principales: políticas y gestión migratoria; derechos humanos; $y$ migración y desarrollo.

Esta comisión se encarga de todo lo relacionado al tránsito y flujo de personas a nivel intrarregional y extrarregional. Según el artículo 8 del Reglamento de la Comisión Centroamericana de Directores de Migración OCAM sus principales funciones son "desarrollar estudios, análisis, programas y mecanismos que faciliten los sistemas migratorios, y favorecer la elaboración de instrumentos que definan políticas públicas migratorias que faciliten la integración regional" (OCAM, 2000).

Según la Organización Internacional para las Migraciones ${ }^{9}$ los ejes de trabajo de la OCAM desde su surgimiento han sido:

- Legislación: Marco legal, convenios, manuales, glosario de términos, legislación interna e internacional, mecanismos políticos para alcanzar validez de un instrumento y programas de regularización.

\footnotetext{
9 Información sustraída de: https://rosanjose.iom.int/site/es/oim-y-ocam
} 
- Sistemas de información: plataforma tecnológica común, software y hardware, intercambio de información, procedimientos de captura de información, obtención y tratamiento de información migratoria, pre chequeo, coordinación de esquemas de migración invisible y sistemas de información avanzada de pasajeros (APIS).

- Derechos humanos: prevención y combate al tráfico ilícito de migrantes y trata de personas, retorno de repatriados, retorno digno, seguro y ordenado de migrantes regionales y extrarregionales, protección a víctimas.

- Seguridad: protección, vigilancia, prevención, modernización de la gestión migratoria, fortalecimiento fronterizo, controles integrados.

- Infraestructura: unificación, mejoras físicas de tecnología, modernización, sanitación de fronteras.

- Documentación de viaje: pasaporte centroamericano, tarjeta de ingreso y egreso, documentación para vehículos, carnet de extranjeros residentes, pase corto a la costa, tarjeta única de embarque.

- Cooperación: proyectos, capacitaciones, investigaciones, asistencia técnica y financiera.

- Trabajo: migración laboral.

- Procedimientos: horarios, permanencias, ingresos, controles integrados, armonización de requisitos de ingreso de extranjeros, cobros o aranceles, trámites, sellado, implementación de instrumentos y procedimientos comunes.
- Política: Compromisos, declaraciones, convenios, reglamentos, homologación de políticas migratorias.

Posteriormente, en 2012, se llevó a cabo una mesa redonda de Alto Nivel llamada "Declaración de Acción de San José" en donde se reunieron los Gobiernos de Belice, Canadá, Costa Rica, El Salvador, Estados Unidos de América, Guatemala, Honduras, México y Panamá. Participaron también Argentina, Brasil, Chile y Uruguay, contaron con el apoyo de otros países interesados, junto con las instituciones nacionales de derechos humanos, las agencias del Sistema de las Naciones Unidas, otras organizaciones regionales e internacionales, organizaciones de la sociedad civil y la Academia, así como con la colaboración y apoyo técnico de la Organización de los Estados Americanos (OEA), el Alto Comisionado de las Naciones Unidas para los Refugiados (ACNUR) y el apoyo del SICA.

La Declaración de Acción de San José incluye los compromisos que los países antes mencionados pretenden cumplir en el área de protección a los centroamericanos que han tenido que emigrar en busca de mejores oportunidades. Uno de los principales puntos en los que coincidieron los países del Triángulo Norte, México, EEUU y Canadá es el reforzar la seguridad física y jurídica de los desplazados, refugiados y solicitantes de asilo.

De esta forma, el Sistema de Integración Centroamericano ha logrado crear un marco jurídico en materia migratoria bastante amplio, sobretodo en el marco de la Agenda 2030 y los ODS. En esta instancia cobra importancia el Marco de la Gobernanza y Migración (MIGOF) aprobado por la OIM mediante la Resolución número 1310 con 
fecha del 24 de noviembre de 2015. Su importancia radica en que dota a los países con tres principios y tres objetivos en materia migratoria.

Los principios de la Resolución son:

1. Adhesión a las normas internacionales $y$ respeto de los derechos de los migrantes

2. Formulación de políticas contrastadas y aplicación de enfoques de gobierno integrados.

3. Colaboración con sus asociados para hacer frente a la migración y a las cuestiones conexas.

Los objetivos son:

1. Fomentar el bienestar socioeconómico de los migrantes y de la sociedad.

2. Abordar eficazmente los aspectos relativos a la movilidad en situaciones de crisis.

3. Velar porque la migración se efectúe de manera segura ordenada y digna ${ }^{10}$. (OIM, 2017)

En la creación de nueva legislación en materia migratoria hay que destacar la participación de las organizaciones de la sociedad civil, tanto de forma individual como de redes estatales y transnacionales que se han venido constituyendo en la región centro y norte americana.

La legislación y las herramientas del SICA para proteger a los migrantes se dividen en dos categorías:

10 El tema de la migración segura ordenada y digna se ha visto desarrollada por el Pacto para la migración Segura Ordenada y Regular aprobado en 2018 y que se desarrollará en los capítulos subsiguientes.

\section{Protección a migrantes en su camino}

Uno de los problemas que más atención requiere por parte del SICA, en cuanto a migración se refiere, es el del respeto de los derechos de las personas en los países de tránsito. En el caso de la migración centroamericana, los países de tránsito según sus rutas son:

\begin{tabular}{l|c|c}
\hline País de origen & Países de tránsito & País de destino \\
\hline E1 Salvador & $\begin{array}{c}\text { Guatemala y } \\
\text { México }\end{array}$ & $\begin{array}{c}\text { EE. UU.y } \\
\text { Canadá (en su } \\
\text { defecto México). }\end{array}$ \\
\hline Guatemala & México & $\begin{array}{c}\text { EE. UU.y } \\
\text { Canadá (en su } \\
\text { defecto México). }\end{array}$ \\
\hline Honduras & $\begin{array}{c}\text { El Salvador, } \\
\text { Guatemala y } \\
\text { México }\end{array}$ & $\begin{array}{c}\text { EE. UU. y } \\
\text { Canadá (en su } \\
\text { defecto México). }\end{array}$ \\
\hline
\end{tabular}

Fuente: Elaboración propia.

El país de tránsito inevitable es México y, por desgracia, este es conocido "como uno de los ejemplos más siniestros en materia de violaciones sistemáticas de los derechos humanos de transmigrantes" (Varela Huerta, 2016). Actualmente México se puede comparar, en cuanto a materia de migración se refiere, a Marruecos y Turquía al ser países "tapón”. ${ }^{11}$

Los países tapón son un fenómeno que algunos investigadores llaman "externalización de las fronteras” (Fernández Bessa, 2008), implicando

11 Un país tapón es: “un territorio donde la frontera se verticaliza en toda su geografía, son países circunvenidos a regiones metropolitanas, como la Unión Europea o Estados Unidos. Como se dijo ya, Marruecos, Turquía y México son tres ejemplos concretos de país 'tapón', naciones que paradójicamente tienen largas tradiciones migratorias, pero que se les han impuesto el papel de 'puerta trasera' para frenar a los millones de migrantes forzados, asilados políticos o migrantes económicos, deportándoles masivamente antes de que consigan llegar a los países del norte a los que se dirigen" (Varela Huerta, 2016). 
que las potencias agregan dispositivos de control judicial, militar y policial en los países de tránsito. Estos dispositivos de control de inmigración se implementan mediante tratados internacionales o acuerdos entre Estados que van disfrazados de Acuerdos de Asociación o de Cooperación Militar contra el terrorismo.

La autora Amarela Varela Huerta explica este modelo de gobernabilidad migratoria de la siguiente manera: "intentan desalentar el éxodo de los migrantes, o si éste ya se produjo, se encarga de la intercepción, detención y deportación de los migrantes a través de una compleja red de tercerización política y económica de dispositivos que involucran lo mismo centros de detención para solicitantes de asilo y migrantes «económicos» que la construcción de infraestructura militar para la «contención» de los movimientos humanos" (Varela Huerta, 2016).

El problema de ese modelo de gobernabilidad migratoria suscita cuando EE. UU. y México aplican la fuerza judicial, policial y militar contra los migrantes, con niveles extremos de violencia $\mathrm{y} \sin$ importarles las violaciones a los derechos humanos y fundamentales.

En dichas fronteras existen faltas graves al debido proceso de solicitud de refugio y no se cumplen los principios básicos de la protección internacional como, por ejemplo:

1. El derecho de asilo (acceso al procedimiento).

2. La no devolución y el no rechazo en frontera.

3. La no sanción por ingreso ilegal o irregular (detenciones arbitrarias).

4. La no discriminación.
Aunque el modelo intenta desalentar la migración y eliminar la que está en tránsito, no resulta efectivo, y encima vulnera derechos fundamentales. El SICA, en este caso, debe proponer nuevos tratados y nuevos acuerdos internacionales que ayuden a los migrantes en sus trayectos porque, mientras tanto, existen las políticas públicas, las leyes de extranjería y los acuerdos de gestión de las migraciones que criminalizan la migración irregular.

\section{Protección a migrantes en su destino}

El destino de las caravanas migrantes es Estados Unidos de América, pero también hay migrantes que deciden quedarse en México o irse hasta Canadá. Estos tres países son con los que el SICA debe trabajar para asegurar un mínimo de derechos a los migrantes desde que la persona llega hasta que resuelve los problemas inmediatos y logra integrarse e incorporarse a la nueva cultura.

Estos países de destino han estado reforzando sus fronteras en los últimos años, especialmente Estados Unidos. Este endurecimiento se da a varios niveles, pero como algunos autores sostienen: "tienen que ver con el debate sobre ciertos aspectos que constituyen parte fundamental de la agenda política de aquel país, así como también de ciertas coyunturas, como son los tiempos electorales. Sin embargo, el examen del porqué de la formulación y adopción de políticas migratorias cada vez más restrictivas plantea algunos elementos de contradicción"(Castillo, 2000).

Aquí entran en juego las políticas exteriores de los países de origen y las de los países de 
destino. Estos últimos refuerzan sus políticas migratorias mientras que los primeros exigen respeto a los derechos humanos de los migrantes y mejores condiciones laborales sin que se les vea el estatus migratorio.

Así pues, EE. UU. tiene diversos acuerdos y tratados con los países del Triángulo Norte centroamericano y México para la protección de los migrantes. Casos como el del TPS ${ }^{12}$ y las ayudas económicas a los países centroamericanos son temas a los que estamos acostumbrados a ver en las noticias, pero poco se da a conocer sobre los esfuerzos de un acercamiento EE. UU.-SICA.

E1 SICA cuenta con diversos acuerdos con los Estados Unidos de América para proteger a los migrantes que provienen de la región. Según el Secretario General del SICA, Vinicio Cerezo, "la migración y la movilidad humana en los países del SICA (...) es un tema complejo que debe abordarse desde una perspectiva humana y de derechos más allá de la seguridad pública” (Cerezo, 2019).

Los esfuerzos del SICA se han multiplicado en los últimos años en vistas de la pérdida de capital humano que tiene la región. La llamada "Política Migratoria Regional Integral", propuesta en $2015^{13}$, fue creada con el objetivo de crear un

12 Estatus de Protección Temporal o conocido por sus siglas en inglés TPS es un beneficio otorgado por los Estados Unidos de América para que los migrantes que cumplan ciertos requisitos puedan vivir y trabajar legalmente de forma provisional. Para conocer más del tema visitar: https:/www.abogado.com/recursos/inmigracion/ humanitario/status-protegido-temporal/

13 Fue presentada en 2015 pero en la XXXV Cumbre de Jefes de Estado y de Gobierno del SICA, celebrada en Panamá en junio de 2010, se acordó: "Reiterar la importancia de contar con una política migratoria regional integral, con una visión intra y extra regional, que marco de actuación del SICA para confrontar los retos de "facilitar la movilidad humana, promover la integración social de las personas migrantes y sus familias, atender las necesidades de los nacionales en los Estados de los países de destino y en las comunidades transfronterizas, entre otras" (SICA, 2015).

México, por su parte, ha estado implementando el Programa Especial de Migración para "consolidar una política migratoria integral, intersectorial y participativa, basada en la promoción de los derechos humanos, el desarrollo sustentable, la equidad de género, la interculturalidad y la seguridad humana”(SICREMI, 2015).

La función de México en la historia reciente es, como se dijo en el apartado anterior, la de un país tapón. Tiene presión de parte de sus vecinos del Norte de fortalecer sus fronteras o aceptar a los migrantes que se encuentran esperando cruzar el río Grande y tiene las peticiones del SICA de que se respeten a los migrantes en tránsito.

Si bien es cierto que el Gobierno de México se ha doblegado ante la presión de la superpotencia de la zona, se ha visto puesto en jaque por varias asociaciones de la sociedad civily ONG para que se resguarden los derechos de los centroamericanos.

considere las legislaciones de los países de origen, tránsito y destino, para lo cual se instruye a la Secretaría General, para que bajo la dirección del Comité Ejecutivo y en coordinación con los gobiernos y las instancias correspondientes de la institucionalidad, presente al Consejo de Ministros de Relaciones Exteriores una propuesta sobre este asunto para ser elevado a la próxima Cumbre Ordinaria que se celebrará en Belice en diciembre de 2010.”y en la XXVI Cumbre de Jefes de Estado y de Gobierno, realizada en Belice en diciembre de 201, se acordó: "Instruir a la S.G. SICA para que con carácter urgente, bajo la dirección del Comité Ejecutivo y en consulta con los gobiernos y las instancias correspondientes de la institucionalidad regional, presente al Consejo de Ministros de Relaciones Exteriores la propuesta de política migratoria regional integral que se encuentra en preparación". 
Es de interés, tanto para México como para los países del SICA, llegar a una formulación de políticas públicas conjuntas y crear una agenda internacional en materia de migración para operacionalizar una solución eficaz.

Como reseña final se hace hincapié a que el SICA establezca una política migratoria conjunta con el fin de fortalecer las negociaciones con países receptores de migración. Esta política migratoria conjunta debe fomentar la creación de redes sociales de migrantes para recopilar información de primera mano de los flujos migratorios, las condiciones de vida de los migrantes en el extranjero y las situaciones de sus familias en los países de origen. Dicha información ayudará a conocer las necesidades de los migrantes y así poder ayudarles en sus países de destino.

\section{Pacto Mundial para la Migración Segura, Ordenada y Regular}

La agenda 2030 fue la que abrió la brecha para mejorar las condiciones de migración de las personas debido a que es un tema presente en varios de los 17 ODS. El más relevante de ellos, en el tema migratorio, es el Objetivo 10: "Reducción de las desigualdades", con su Meta 10.7: "Facilitar la migración y la movilidad ordenadas, seguras, regulares y responsables de las personas, incluso mediante la aplicación de políticas migratorias planificadas y bien gestionadas".

Con la creación de la ya mencionada Agenda 2030 y los ODS y su entrada en vigor en 2016, el Secretario General de la ONU publicó un informe que se titulaba En condiciones de seguridad y dignidad: respuesta a los grandes desplazamientos de refugiados migrantes. Dicho informe fue el que abrió la "ruta de una Cumbre Extraordinaria en septiembre de ese mismo año, traducida a la postre en la Declaración de Nueva York ${ }^{14}$, en cuyo nombre los Estados miembros de la ONU acordaron compartir la responsabilidad de acoger y prestar ayuda a los migrantes, con el ánimo de concretar, en 2018, la aprobación de un «Pacto Mundial sobre Migración» en aras de configurar un sistema de gobernanza mundial para acometer la movilidad humana" (Silva, Ramsenia, \& Almansa Martínez, 2018).

E1 Pacto Mundial para la Migración Segura, Ordenada y Regular "es un acuerdo global de la ONU sobre un enfoque común sobre la migración internacional en todas sus dimensiones" (ONU, 2018b). Aunque el Pacto no es jurídicamente vinculante para los países firmantes, sino que pretende constituir una oportunidad para mejorar la cooperación en materia de migración.

La migración es un tema actual y según el Pacto debe ser tratado a escala mundial basándose en la cooperación internacional. Dicho pacto no establece un derecho humano a emigrar sino que "aspira a mejorar la cooperación en el ámbito de la migración internacional. No fomenta la migración ni disuade de ella. El Pacto no creará nuevas categorías jurídicas. Hace hincapié en que los migrantes tienen los mismos derechos universales y libertades fundamentales que cualquier otra persona" (Comisión Europea, 2018).

14 "El 19 de septiembre de 2016, la Asamblea General de las Naciones Unidas (ONU), adoptó una serie de compromisos para mejorar la protección de los refugiados y migrantes. Estos compromisos se conocen como la Declaración de Nueva York Sobre Refugiados y Migrantes." Para mayor información consultar: https://www.acnur. org/declaracion-de-nueva-york-sobre-refugiados-y-migrantes.html 
E1 Pacto incluye 23 objetivos para lograr una migración segura, ordenada y regular en todo el ciclo migratorio y son:

1. Recopilar y utilizar datos exactos y desglosados para formular políticas con base empírica.

2. Minimizar los factores adversos y estructurales que obligan a las personas a abandonar su país de origen.

3. Proporcionar información exacta y oportuna en todas las etapas de la migración.

4. Velar por que todos los migrantes tengan pruebas de su identidad jurídica y documentación adecuada.

5. Aumentar la disponibilidad y flexibilidad de las vías de migración regular.

6. Facilitar la contratación equitativa y ética y salvaguardar las condiciones que garantizan el trabajo decente.

7. Abordar y reducir las vulnerabilidades en la migración.

8. Salvar vidas y emprender iniciativas internacionales coordinadas sobre los migrantes desaparecidos.

9. Reforzar la respuesta transnacional al tráfico ilícito de migrantes.

10. Prevenir, combatir y erradicar la trata de personas en el contexto de la migración internacional.
11. Gestionar las fronteras de manera integrada, segura y coordinada.

12. Aumentar la certidumbre y previsibilidad de los procedimientos migratorios para la adecuada verificación de antecedentes, evaluación y derivación.

13. Utilizar la detención de migrantes solo como último recurso y buscar otras alternativas.

14. Mejorar la protección, asistencia y cooperación consulares a lo largo de todo el ciclo migratorio.

15. Proporcionar a los migrantes, acceso a servicios básicos.

16. Empoderar a los migrantes y las sociedades para lograr la plena inclusión y la cohesión social.

17. Eliminar todas las formas de discriminación y promover un discurso público con base empírica para modificar las percepciones de la migración.

18. Invertir en el desarrollo de aptitudes y facilitar el reconocimiento mutuo de aptitudes, cualificaciones y competencias.

19. Crear las condiciones necesarias para que los migrantes y las diásporas puedan contribuir plenamente al desarrollo sostenible en todos los países.

20. Promover transferencias de remesas más rápidas, seguras y económicas y fomentar la inclusión financiera de los migrantes. 
21. Colaborar para facilitar el regreso y la readmisión en condiciones de seguridad y dignidad, así como la reintegración sostenible.

22. Establecer mecanismos para la portabilidad de la seguridad social y las prestaciones adquiridas.

23. Fortalecer la cooperación internacional y las alianzas mundiales para la migración segura, ordenada y regular.

Según la Comisión Europea para América Latina "comprende acciones concretas que ayudarán a los Estados miembros a reducir la migración irregular, por ejemplo, gracias a una mayor cooperación para tratar los factores de la migración, luchar contra la trata de seres humanos y el tráfico ilícito de migrantes, gestionar las fronteras y facilitar el retorno. El Pacto también se centrará en encontrar vías para la migración regular"(Comisión Europea, 2018).

El Pacto es aún muy reciente como para observar y analizar el impacto que ha tenido en la migración, pero se puede hacer una previsión de sus resultados. Es obvio que lo ideal sería un funcionamiento completo del Pacto en la región centroamericana, pero la realidad, desgraciadamente, será otra.

De momento hay que destacar que la OCAM se ha propuesto "apropiarse y participar activamente en la construcción de la agenda global sobre migraciones a través del Pacto Mundial" (Pisani, 2015). Es decir que hoy por hoy es el documento más importante para certificar un trato adecuado a los migrantes y para reforzar la cooperación regional y extra regional en materia de Derechos Humanos para los migrantes.
Es, en definitiva, un documento innovador en materia de migración por su naturaleza global y por abordar el fenómeno en todas sus dimensiones. Cubre las necesidades de los migrantes, los gobiernos, y sociedad civil. Este último, hay que mencionar, es un actor trascendental en todos los objetivos del Pacto es la Sociedad Civil. Se encuentra desde el primer objetivo con la recolección de datos exactos y de primera mano hasta el fortalecimiento de la cooperación internacional.

Finalmente, sería bueno seguir de cerca el posible establecimiento de la nueva Red de Naciones Unidas sobre Migración. Según el Secretario General de la ONU esta Red funcionaria como un método de "garantizar un apoyo efectivo y coherente del sistema de las Naciones Unidas a los Gobiernos en la implementación del Pacto" (ONU, 2018a).

\section{Evaluaciones y Conclusiones}

Las caravanas migrantes han venido a cambiar el panorama político y jurídico actual y los gobiernos y el SICA deben estar a la altura de la situación: deben dejar de ser pasivos y comenzar a integrar los diversos temas de migración en su planificación a largo plazo, generar planes de prevención de migración a niveles locales, nacionales y regionales.

Los únicos dos factores regionales que pueden condicionar el avance de las reformas migratorias son el económico y el social. La respuesta más inmediata a estos condicionantes es la cooperación internacional que, por medio de tratados y acuerdos regionales, ayudaría a la región a obtener una protección más eficiente de los derechos humanos de los migrantes. 
E1 SICA debe cumplir con la promesa de llevar a cabo talleres regionales para capacitar a las personas sobre la migración, dar a conocer a la población potencialmente migrante sus derechos. Deben buscar el apoyo de ACNUR para poder sensibilizar a la comunidad sobre los peligros de migrar de manera irregular y los riesgos que corren al marchar indocumentados.

Hacen falta espacios de cooperación e intercambio de buenas prácticas a nivel nacional y transnacional para prevenir los desplazamientos forzosos. Si con estas herramientas no logran prevenir la migración, el SICA debe recurrir a la cooperación internacional para intentar que tanto los países de origen como los de acogida, aprovechen el potencial de los migrantes por medio de un proceso de globalización inclusivo.

También desde el ámbito académico tenemos la obligación de fomentar la creación de organizaciones para la defensa de los derechos de los migrantes; y además incentivar a las ya existentes para que velen por la reversión de la precariedad jurídica de las caravanas.

Debemos seguir recolectando información y produciendo conocimientos académicos para hacer valer los derechos de los migrantes tanto en los países de tránsito como de destino. También es imprescindible acompañar al migrante en su travesía, describir por lo que está pasando desde su origen hasta su destino, pensar en sus acciones y sus demandas, explicándolas desde lo académico para "desmontar con argumentos de las propias víctimas del llamado 'régimen global de fronteras', el modelo de racismo social e institucional que hoy tiene sumida a toda la humanidad en una de sus crisis de derechos fundamentales más agudas en su historia contemporánea" (Varela Huerta, 2016).

También se debe tener en cuenta que el movilizar una caravana migrante formada por cientos de personas es una tarea difícil, principalmente por las tensiones internacionales que genera debido a la atención mediática y por verificar que se cumplan los derechos de todos los involucrados. Es decir, hay que estudiar tanto a las caravanas como a las personas que están organizándolas para tener un panorama más amplio sobre las condiciones de los migrantes y así poder evitarlas.

Todos los puntos tratados como causales de las caravanas migrantes se ven unidos entre sí y el SICA debe intentar contrarrestarlos de manera conjunta. Básicamente, el grado de prosperidad de las economías centroamericanas en el futuro cercano afectará el ingreso per cápita de sus habitantes, lo que a su vez generará una disminución de la violencia, una redistribución de la riqueza y eso influirá en el nivel de educación de la población y esto se puede aprovechar para generar mayor conciencia ambiental.

Para los Gobiernos e instituciones internacionales gestionar estas caravanas migrantes de forma eficaz resulta ser una tarea titánica y se debe "asumir un enfoque holístico que favorezca el tratamiento humano de los migrantes -independientemente de su estatus migratorio-, poniendo en primer plano la totalidad de sus dimensiones y aspectos esenciales como personas" (Silva et al., 2018).

El SICA, por su parte, ha intentado mejorar las condiciones económicas, sociales, de seguridad y de medioambiente en un intento de desalentar a las personas a migrar, pero con los recientes 
éxodos ha quedado retratada su incapacidad de gestión. "En este sentido, al hacer una evaluación de la legislación migratoria en México y Centroamérica, se ha constatado que existen limitaciones en el diseño y ejecución de medidas que promuevan y protejan los derechos humanos de las personas migrantes, especialmente en los temas de integración e inclusión social"(CEPAL, 2018).

La realidad es que hay más de 3,800 personas que han migrado en masa y millones más que han migrado a lo largo de los últimos años y a todos ellos no les sirven de nada las leyes y políticas públicas para evitar la migración. A ellos hay que proporcionarles otro tipo de cuidados, tales como: asegurarles sus derechos humanos tanto en su ruta como en su destino y tratar de mejorar sus países de origen para intentar que regresen.

Los derechos humanos de las personas migrantes en las caravanas se han visto vulnerados en diversas ocasiones y los Gobiernos e instituciones no se han involucrado lo suficiente o simplemente no han estado presentes. "Esto se debe a que las políticas migratorias que tienen no corresponden a un enfoque de derechos humanos, de seguridad humana, es decir, no ponen a la persona migrante en el centro" (Martínez Hernández-Mejía, 2018).

Para garantizar los derechos de los migrantes se deben hacer nuevas leyes en materia migratoria con la participación de la sociedad civil y organizaciones no gubernamentales. A estas últimas se les puede aumentar el marco de actuación, sobre todo en su rol de interlocutoras para dependencias de instituciones estatales que atienden a los migrantes.
Ahora bien, la nueva legislación que se vaya produciendo debe ser reforzada con la armonización de la Constitución Política de cada país involucrado. Esto partiendo desde la premisa que "no hay uniformidad temporal ni temática en esta armonización en los países de la subregión; no obstante, todos cuentan con una ley que aborda específicamente la materia migratoria. En general, existen disposiciones inconsistentes o incompatibles con el respeto y salvaguarda de derechos u omisas en el establecimiento de condiciones que garanticen el efectivo y adecuado ejercicio de los derechos" (Bonnici, 2011).

Las caravanas migrantes son un fenómeno ya finalizado y probó una eficacia de migración muy pobre. Probaron ser muy poco eficaces a la hora de transmitir un mensaje sociopolítico y como método migratorio irregular, por ello se podría esperar que esos éxodos ya no ocurran, y si lo hacen ya sería bajo nuevas condiciones y nuevos lineamientos.

Finalmente resaltar que, aunque es difícil conocer la historia de cada una de las personas que han migrado en caravanas, sería bueno hacer un estudio sociohumanístico sobre el desenlace de sus travesías. Además, para profundizar en el tema de las caravanas migrantes se recomienda realizar un estudio sobre la demografía de las personas migrantes y los niños no acompañados que iban en estos éxodos además de las políticas de ayudas al retorno de migrantes del SICA.

\section{Bibliografía}

Abuelafia, E. (2018). La politica migratoria de los EE. UU. y su impacto en el Triángulo Norte de Centroamérica. Washington DC: Inter-American Development Bank. 
AECID. (2018). Proyecto B.E.1. Prevención Social de la Violencia desde los Gobiernos Locales en Centroamérica. San Salvador. Retrieved from http://www.aecid.sv/wp-content/ uploads/2018/04/Terminos-de-Referencia-para-Estudio-de-oferta-y-demanda-del-mercado-laboral-local-en-los-Municipios-Atescatempa-Camotan-y-Santa-Catarina-Mita-de-la-Republica-de-Guatemala..pdf

Banco Interamericano de Desarrollo. (2006). La cohesión social en America Latina y el Caribe. Análisis, Acción Análisis, Acción y Coordinación. Washington DC: Autor.

BBC News. (2018). Migrant caravan: What is it and why does it matter? BBC. Retrieved February 1, 2019, from https://www.bbc.com/ news/world-latin-america-45951782

Bonilla Silva, J. P. (2017). Comisión Centroamericana de Ambiente y Desarrollo. Informe Integrar. n. 105.

Bonnici, G. et al. (2011). Estudio comparativo de la legislación y politicas migratorias en Centroamerica, México y República Dominicana. México: Instituto Centroamericano de Estudios Sociales y Desarrollo.

Buvinic, M., Morrison, A., \& Shifter, M. (2018). La Violencia en América Latina y el Caribe: Un Marco de Referencia para la Acción. Washington D.C. Recuperado de: https:// publications.iadb.org/publications/spanish/ document/La-violencia-en-América-Latinay-el-Caribe-Un-marco-de-referencia-parala-acción.pdf
Callen, T. (2008). ¿ Qué es el producto interno bruto. Finanzas E Desarrollo, 48.

Castillo, M. Á. (2000). Las políticas hacia la migración centroamericana en países de origen, de destino y de tránsito. Papeles de Población, 6(24), 133-157.

CCAD. (2008). Estado de la Región. San Salvador, E1 Salvador.

CCAD. (2013). Sistema de la Integración Centroamericana (SICA). Recuperado de: https://www.sica.int/ccad/breve.aspx

CEPAL. (2007). Cohesión Social, Inclusión y sentido de pertenencia en América Latina y el Caribe. México: Autor.

CEPAL. (2016). Agenda 2030 para el Desarrollo Sostenible | Comisión Económica para América Latina y el Caribe. Recuperado de: https://www. cepal.org/es/temas/agenda-2030-desarrollosostenible

CEPAL. (2019). CEPALSTAT. Recuperado de: http://estadisticas.cepal.org/sisgen/ConsultaIntegrada.asp?IdAplicacion=6\&idTema=131\&idIndicador $=2206 \&$ idioma $=\mathrm{e}$

CEPAL. (2018). Informe final de la Reunión Regional Latinoamericana y Caribeña de Expertas y Expertos en Migración Internacional preparatoria del Pacto Mundial para una Migración Segura, Ordenada y Regular. Santiago de Chile: Autor.

Cerezo, V. (2019). Presentación del Informe de Ejecución Programática y Presupuestaria 
2018 en Asamblea Plenaria del Parlamento Centroamericano. San Salvador, E1 Salvador.

CIS/SICA. (2009). Fondo Estructural de Cohesión Social para Centroamérica. San Salvador, El Salvador. https://doi.org/Serie Integración 1

Comisión Europea. (2018). ¿¿Qué es el Pacto Mundial para una Migración Segura, Ordenada y Regular? Bruselas, Bélgica: Autor.

Cortina, J., De la Garza, R., Ochoa-Reza, E. (2005). Remesas: límites al optimismo. Foreign Affairs En Español, 5(3), 27-36.

El Sol de México. (2018). Enfrentamiento entre policías y migrantes deja un muerto. Recuperado de: https://www.elsoldemexico. com.mx/mexico/sociedad/enfrentamientoentre-policias-y-migrantes-deja-unmuerto-2392968.html

Equipo Regional de Monitoreo y Análisis de Derechos Humanos en Centroamérica. (2019). Homicidios en Centroamérica. San Salvador . Recuperado de: http://regionsegura. com/wp-content/uploads/2019/02/BoletínCentroamericano-febrero-2019-Homicidiosen-Centroamérica-2018.pdf

Europa Press. (2018). Una nueva caravana con 2.000 migrantes sale de El Salvador rumbo a EEUU. Europa Press. Recuperado de: https:// www.europapress.es/internacional/noticianueva-caravana-2000-migrantes-sale-salvadorrumbo-eeuu-20181031165205.html

Fernández Bessa, C. (2008). Introducción: los limites del control. Frontera Sur. Nuevas Politicas de Gestión y Externalización Del Control de La Inmigración En Europa, 7-12.

Guerrero, J., García, B. (2012). Violencias en Contexto. Bogotá: Universidad Distrital Francisco José de Caldas.

Jiménez, F. (2012). Conocer para comprender la violencia: origen, causas y realidad. Convergencia, Revista de Ciencias Sociales, 19(58), 13-52.

Lera Mejía,J.A.(2018).Éxodo de transmigrantes centroamericanos y tráfico de personas: Relatos de una cruda realidad. Casos de familias enteras a través de México y Tamaulipas. Bloomington, Estados Unidos: Palibrio.

MartínezHernández-Mejía,I.(2018).Reflexiones sobre la caravana migrante. Guadalajara: Instituto Tecnológico y de Estudios Superiores de Occidente, ITESO.

Martínez, S., \& Briscoe, I. (2019). Las políticas que engendraron el éxodo. Política Exterior, 33(187), 116-123.

Meyers, D. W. (2000). Remesas de América Latina: revisión de la literatura. Comercio Exterior, 50(4).

OCAM. Reglamento de la Comisión Centroamericana de Directores de Migración (2000). El Salvador. Recuperado de: https:// www.sica.int/download/?95519

OIM. (2017). La OIM y la Agenda 2030 para el desarrollo sostenible en América Latina y el Caribe. Recuperado de: https://goo.gl/YdrrC1 
ONU. (2018a). Pacto Mundial sobre Migración, Conferencia Intergubernamental,2018 Marrakech. Recuperado de: https://www.un.org/es/conf/ migration/faqs.shtml

ONU. (2018b). Pacto Mundial sobre Migración, Conferencia Intergubernamental. Conferencia Intergubernamental. Recuperado de: https:// www.un.org/es/conf/migration/global-compact-for-safe-orderly-regular-migration.shtml

Pisani, M. (2015). Cuatro oportunidades para fortalecer la proyección de la OCAM. En Movimiento. Recuperado de: https://rosanjose. iom.int/site/es/blog/cuatro-oportunidadespara-fortalecer-la-proyecci-n-de-la-ocam

Protocolo de Tegucigalpa. (1991). Protocolo de Tegucigalpa a la Carta de la Organización de Estados Centroamericanos, suscrito en Tegucigalpa. Honduras, 13.

SICA. (2014). Estrategia de Seguridad de Centroamérica - ESCA. Recuperado de: https:// www.sica.int/consulta/documento.aspx?id$\mathrm{n}=84016 \& \mathrm{idm}=1 \& \mathrm{IdEnt}=1065$

SICA. Propuesta de Política Migratoria Regional Integral (2015). Costa Rica. Recuperado de: http://www.parlacen.int/Portals/0/ ForoOrganosComunitarios/Documentos/ MIGRACIONPropuestadePolMig. Reg. Integra1220515ConsensuadaDirectorioOCAM_E...pdf

SICREMI. (2015). Migración Internacional en las Américas. Washington D.C. Recuperado de: https://www.oas.org/docs/publications/sicremi2015-spanish.pdf
SIECA. (2019). ¿Qué es la SIECA? - SIECA. Recuperado de: https://www.sieca.int/index. php/acerca-de-la-sieca/informacion-general/ que-es-la-sieca/

Silva, C., Ramsenia, A., Almansa Martínez, A. (2018). Migración: retos y oportunidades desde la perspectiva de los Objetivos de Desarrollo Sostenible (ODS). Revista de Ciencias de la Administración. Vol. 8, n. ${ }^{\circ} 16$, pp. 109-120.

SISCA. (2009). Bases para una politica social Centroamericana. San Salvador, El Salvador. https://doi.org/2 Serie Integración

Sojo, C. (2007). Cohesión social y exclusión. Una mirada desde Centroamérica. Revista de pensamiento iberoamericano, n. ${ }^{\circ} 18$, pp.76-87.

Técnico Intersectorial -Sica, C. (2018). Agenda Regional Intersectorial sobre Protección Social e Inclusión Productiva con Equidad (ARIPSIP) 2018-2030. Recuperado de: https://www. sisca.int/centro-de-documentacion/marcoestrategico/1025-agenda-regional-intersectorialsobre-proteccion-social-e-inclusion-productivacon-equidad-aripsip-2018-2030-1/file

UNHCR ACNUR. (2018). "Caravanas" de refugiados y migrantes en Centro América. México. Recuperado de: https://www.acnur. org/5bf3380e4.pdf

Varela Huerta, A. (2016). Luchas migrantes en contextos de tránsito migratorio, el caso del Movimiento Migrante Centroamericano. REMHU-Revista Interdisciplinar Da Mobilidade Humana, 24(48). 